\title{
Biosurfactant, polythene, plastic, and diesel biodegradation activity of endophytic Nocardiopsis sp. mrinalini9 isolated from Hibiscus rosasinensis leaves
}

\author{
Mrinalini J Singh ${ }^{*}$ and Padmavathy Sedhuraman
}

\begin{abstract}
Background: Endophytic non-streptomycetes group of actinomycetes from Hibiscus rosasinensis leaves were screened for biosurfactant, polythene, plastic, and diesel biodegradation activities. Biosurfactant activity was evaluated by hemolysis, drop-collapsing test, lipase production, oil-spreading technique, bacterial adhesion to hydrocarbon (BATH) assay, penetration assay, and emulsification assay. Similarly, polythene, plastic, and diesel biodegradation activity were also carried out.

Findings: Among the five non-streptomycetes isolates, only one newly found actinomycete isolate named as A9 exhibited significant biosurfactant and biodegradation activity. Based on Bergey's manual of systematic bacteriology, the strain A9 was similar to Nocardiopsis sp. Molecular characterization and phylogenetic analysis support the classification of the isolate as a new strain which was named as Nocardiopsis sp.mrinalini9. The isolate was closely related to the type strain of Nocardiopsis synnemataformans sharing a 16S rRNA gene sequence similarity of 99\%. The partial 165 rRNA sequence of the isolate (1061 bp) was deposited in Genebank under the accession number KF909126. Still, DNA-DNA hybridizations, phenotypic comparisons, and chemotaxonomic analysis need to be performed to confirm its novelty.

Conclusion: It is evident from the study that rare endphytes associated with medicinal plants has got excellent hydrocarbon biodegradation capacity.
\end{abstract}

Keywords: Biosurfactant; Biodegradation; Bergey's manual of systematic bacteriology; Nocardiopsis sp.mrinalini9

\section{Findings}

\section{Introduction}

Surfactants like wetting agents or petroleum derivatives lower the surface tension between two liquids or between a liquid and a solid. But, they are non-degradable leading to toxic effects. To solve this difficulty, eco-friendly microbes were explored for biosurfactant property with high solubility, high biodegradability, and low toxicity with diverse applications.

Though plastic and polythene are durable and strong with wide applications, they seem to be non-degradable leading to severe pollution issues by disturbing the whole ecosystem. Even their recycling are not followed widely due to economic viability.

* Correspondence: mrinalini.singh50@gmail.com

Department of Botany, Nirmala college for Women, Red fields, Coimbatore 641018, Tamilnadu, India

\section{Springer}

(c) 2015 Singh and Sedhuraman; licensee Springer. This is an Open Access article distributed under the terms of the Creative Commons Attribution License (http://creativecommons.org/licenses/by/4.0), which permits unrestricted use, distribution, and reproduction in any medium, provided the original work is properly credited.
Similar to plastic issues, even the hydrocarbons like petrol and diesel spills seem to be the global environmental pollutant causing deleterious pollution effects in spite of being the principle source of energy. Successful application of bioremediation technology solely depends on in situ application of a microbial consortium with high biodegradation capacity.

Yousaf et al. [1] isolated hydrocarbon degraders Pseudomonas, Arthrobacter, Enterobacter, and Pantoea species from the root and stem tissues of Italian ryegrass and birds foot trefoil vegetated in hydrocarbon-contaminated soil. Similarly, Siciliano et al. [2] found that endophytic hydrocarbon degraders in tall fescue (Festuca arundinacea) and rose clover (Trifolium fragiferum) at an aged-hydrocarboncontaminated site with up to $4 \%$ of culturable endophytes possessing genes involved in hydrocarbon degradation. 
There is increasing interest in the role of endophytes in phytoremediation application as they can serve as vector delivering biodegradative capacities inside the plant [3]. However, it is not fully understood, whether potentially degrading endophytes are active once inside the plant and thereby contribute to the detoxification of the pollutant and better survival of the plant under toxic conditions.

Hence, the screening of effective microbes among the diverse marine and terrestrial microbial communities has been carried out worldwide for the last few decades. Our search especially focused on least-explored endophytic non-streptomycetes actinobacteria isolated from less-explored medicinal plants since the search for rare isolates proved to be the treasure house of bioactivity with varied applications. Endophytic actinomycetes were usually explored for antimicrobial activities and plant growth promotion studies. This might be the first report which led to the discovery of potent endophytic Nocardiopsis sp. mrinalini9, a new endophytic strain with good biosurfactant and biodegradation property which could address the serious environmental issues.

\section{Materials and methods Sample collection}

Healthy leaf samples of common medicinal plant Hibiscus rosasinensis were gathered from the garden of Nirmala College for Women, Coimbatore $\left(11.0183^{\circ} \mathrm{N}, 76.9725^{\circ} \mathrm{E}\right)$ surrounded by Western Ghats of Southern India during the period of December 2011 to January 2012. The collected plant materials were taken to the laboratory, preserved at $4^{\circ} \mathrm{C}$ in sealed plastic bags, and subjected to isolation work within $96 \mathrm{~h}$.

\section{Isolation of endophytic actinobacteria}

Healthy leaf samples were cut into small pieces $(2 \times 2 \mathrm{~cm})$ and washed by running tap water for 1-2 min to remove the soil particles completely. The resultant were subjected to a five-step surface sterilization procedure as per the method of Sheng et al. [4]: a 4- to 10-min wash in 5\% sodium hypochlorite, followed by a 10 -min wash in $2.5 \%$ sodium sulphite, a 5-min wash in $75 \%$ ethanol, a wash in sterile water, and a final rinse in $10 \%$ sodium bicarbonate for $10 \mathrm{~min}$ to disrupt the plant tissues and inhibit the fungal growth. At this point, the final washed solution was spread onto ISP 2 (yeast extract malt extract agar) and observed for microbial growth to validate the surfacesterilized protocol and the result was negative. After the sterility check, the surface-sterilized tissues were subjected to continuous drying at $100^{\circ} \mathrm{C}$ for $15 \mathrm{~min}$. The surfacetreated samples were aseptically transferred on humic acid vitamin agar and incubated at $28^{\circ} \mathrm{C}$ for 2 to 8 weeks [4]. Then, they were purified on yeast extract malt extract agar and incubated at room temperature $\left(28 \pm 2^{\circ} \mathrm{C}\right)$ for 30 days.

\section{Screening methods for biosurfactant assay}

Biosurfactant assay was determined for the pure culture of actinobacteria by seven different methods, namely, (i) hemolysis, (ii) drop-collapsing test, (iii) lipase test, (iv) oil-spreading technique, (v) bacterial adhesion to hydrocarbon (BATH) assay, (vi) penetration assay, and (vii) emulsification assay.

Hemolysis activity Biosurfactant assays of the isolates were evaluated by the hemolysis test on blood agar plate. The isolates were streaked on the blood agar and the plates were incubated at $28^{\circ} \mathrm{C}$ for 7 days. The plates were then observed for zone of clearance around the colonies as discussed elsewhere [5,6].

Drop-collapsing test Two microliters of mineral oil was added to a 96-well microtitre plate and equilibrated for $1 \mathrm{~h}$ at $37^{\circ} \mathrm{C}$. Five microliters of the culture supernatant was added to the surface of the oil in well. The shape of drop on the oil surface was noted after $1 \mathrm{~min}$. The culture supernatant that collapsed the oil drop was indicated as positive, and the culture supernatant which failed to collapse the oil drop was indicated as negative. Distilled water was used as negative control. The procedure is discussed elsewhere with slight modifications [6,7].

Oil-spreading technique In oil-spreading assay, as discussed by Morikawa et al. [8], $10 \mu \mathrm{L}$ of crude oil was added to the surface of $40 \mathrm{~mL}$ of distilled water in a Petri dish to form a thin oil layer. Then, $10 \mu \mathrm{L}$ of culture or culture supernatant were gently placed on the center of the oil layer. The presence of biosurfactant would displace the oil and a clear zone would form. The diameter of the clearing zone on the oil surface would be visualized under visible light and measured after $30 \mathrm{~s}$, which correlates to the surfactant activity, also known as oil displacement activity.

Bacterial adhesion to hydrocarbons The hydrophobicity of the cells can be measured by BATH assay as discussed by Rosenberg et al. [9]. Actinobacterial cells were washed twice with phosphate buffer salt solution and were suspended in it to give an optical density of $\sim 0.5$ at $600 \mathrm{~nm}$. One hundred microliters of crude oil (diesel) was added to $2 \mathrm{~mL}$ of cell suspension and was vortex-shaken for $3 \mathrm{~min}$ in test tubes. After shaking, crude oil and aqueous phase were allowed to separate for $1 \mathrm{~h}$. Optical density of the aqueous phase was then measured at $600 \mathrm{~nm}$ in a spectrophotometer. Hydrophobicity is expressed as the percentage of cell adherence to crude oil and was calculated as follows: 
$100 *$ (1-optical density of the aqueous phase/ optical density of the initial suspension)

Three independent determinations were made and the mean values were calculated.

Penetration assay This assay relies on the contact of two insoluble phases which leads to a color change as described by Maczek et al. [10].

In this assay, the cavities of a 96-well microplate were filled with $150 \mu \mathrm{L}$ of a hydrophobic paste made up of oil and silica gel. This separated paste was covered with $20 \mu \mathrm{L}$ of oil. Then, $10 \mu \mathrm{L}$ of a red-staining solution (safranin) was added to $90 \mu \mathrm{L}$ of the supernatant. That colored supernatant was then placed on the surface of the oil-covered paste.

Emulsification assay Emulsification assay was carried out using petroleum as described by Cooper et al. [11].

Two milliliters of hydrocarbon, i.e., petrol was taken in a test tube to which $1 \mathrm{~mL}$ of cell-free supernatant obtained after centrifugation of the culture was added and was vortexed for 2 min to ensure homogenous mixing of both the liquids. The emulsification activity was observed after $24 \mathrm{~h}$ and it was calculated by using this formula:

Total height of the emulsion/Height of the aqueous layer $* 100$

\section{Plastic degradation}

Plastic degradation steps were followed as per the standard procedure with slight modifications, as discussed by Kathiresan [12]. The fresh polythene bags and disposable plastic cups were collected and heat-dried at $40^{\circ} \mathrm{C}$ in hot air oven for 14 days and then cut into small discs of $1-\mathrm{cm}$ diameter. Pre-weighed polythene and plastic discs of $100 \mathrm{mg}$ were aseptically transferred to conical flasks as separate batches containing $50 \mathrm{~mL}$ of sterile $0.3 \%$ yeast extract broth, inoculated with actinomycetes culture. Control was maintained with polythene and plastic discs in the microbe-free medium. All these flasks were left in a shaker at $37^{\circ} \mathrm{C}$ for bacterial cultures and $28^{\circ} \mathrm{C}$ for actinomycetes cultures for 2 months maintaining 180 revolutions/min. After 2 months of incubation, the polythene and plastic discs were washed thoroughly with distilled water and dried over night at $45^{\circ} \mathrm{C}$, and then final weight was measured. From the data collected, weight loss of the plastic strip was calculated.

\section{Diesel degradation}

Diesel degradation steps were followed as per the standard procedure with slight modifications, as discussed by Smita et al. [13]. For confirming the diesel biodegradation ability of the test isolates, Bacto Bushnell Haas broth was used. The pure culture isolates were introduced into $50 \mathrm{~mL}$ of
Bacto Bushnell Haas broth incorporated with sterile diesel $(1 \% v / v)$. Control was maintained with only $1 \%$ sterile diesel in the microbe-free medium. All these flasks were left in a shaker at $28^{\circ} \mathrm{C}$ for actinomycetes cultures for 7 days maintaining 180 revolutions/min. The aliquots in the flask were monitored daily for color change from deep blue to pink and then colorless. On a daily basis, $5 \mathrm{~mL}$ of the aliquots were collected from each flask and the absorbance was noted on spectrophotometer at $600-\mathrm{nm}$ wavelength.

Vapor phase transfer diesel utilization test was carried out for the confirmation of actual diesel utilizing microbes with the isolates that showed faster color change in the primary step as per the standard procedure $[13,14]$. The isolates that showed faster color change were streaked on mineral salt agar media. The inner side of the Petri dish was covered with a sterile filter paper (Whatman no. 1) saturated with filter-sterilized diesel. Through vapor phase transfer, diesel was used as sole carbon and energy source for the growth of microbes. All the plates were kept inverted and incubated at $28^{\circ} \mathrm{C}$ for 7 to 14 days for the growth of diesel utilizers.

\section{Identification of actinomycetes}

The isolates were identified according to morphological criteria, including characteristics of colonies on plate, morphology of substrate and aerial hyphae, morphology of spores, and pigment production as discussed elsewhere $[15,16]$. These isolates were preserved in $20 \%(v / v)$ glycerol for subsequent investigation.

\section{Molecular identification}

DNA from the potent strain was isolated employing Chromous DNA isolation kit (Chromous Biotech, Bangalore, India) according to the manufacturer protocol. The $16 \mathrm{~S}$ rRNA gene fragment was amplified by using universal primers corresponding to positions 8 to 27 for the forward primer and 1492 to 1510 for the reverse primer mentioned below (Table 1).

Forward primer: 5'-AGAGTTTGATCMTGGCTCAG-3'

Reverse primer: 5'-TACGGYTACCTTGTTACGACTT-3'

Sequencing was performed by using Big Dye terminator cycle sequencing kit (Applied BioSystems, Waltham, MA, USA). Sequencing products were resolved on an Applied Biosystems model 3500XL automated DNA sequencing system (Applied BioSystems, USA). Nucleotide sequence

\begin{tabular}{lllll}
\multicolumn{5}{l}{ Table $\mathbf{1}$ PCR amplification protocol } \\
\hline $94^{\circ} \mathrm{C}$ & $94^{\circ} \mathrm{C}$ & $55^{\circ} \mathrm{C}$ & $72^{\circ} \mathrm{C}$ & $72^{\circ} \mathrm{C}$ \\
$5 \mathrm{~min}$ & $30 \mathrm{~s}$ & $30 \mathrm{~s}$ & $1 \mathrm{~min}$ & $5 \mathrm{~min}$ \\
$\begin{array}{l}\text { Initial } \\
\text { denaturation }\end{array}$ & Denaturation & Annealing & Extension & $\begin{array}{l}\text { Final } \\
\text { Extension }\end{array}$ \\
& $35 \mathrm{cycles}$ & & & \\
\hline
\end{tabular}


of $16 \mathrm{~S}$ rRNA gene from actinomycetes strain was determined and compared for similarity level with the reference species present in genomic database bank using NCBI BLAST program multiple sequence alignment, and the phylogenetic tree was constructed using MEGA software as described by Tamura et al. [17].

\section{Results and discussion \\ Biosurfactant assay}

Yeast extract malt extract agar plates spread with the last water from the washing of plant samples failed to grow colonies of microorganisms after 2 weeks of incubation. This indicated that the five-step surface sterilization protocol was effective at killing the epiphytic microorganisms. Thus, the subsequent isolates can be considered true endophytes.

Aseptical transfer of surface-treated $H$. rosasinensis leaf samples and subsequent plating on ISP agar resulted in isolation of five non streptomycetes colonies. Only one non-streptomycetes isolate named as A9 showed distinct biosurfactant, diesel, polythene, and plastic degradation.

On blood agar, it showed a clear zone around the colonies causing lysis of blood (Figure 1).

In the drop collapsing test, a drop of surfactant producing culture was flattened on oil surface leading to positive reaction. A9 provided complete spreading due to the reduction in force or interfacial tension between the liquid drop and the hydrophobic surface. The stability of drops is dependent on surfactant concentration and correlates with surface and interfacial tension.

In oil-spreading technique, when the supernatant of the given strain was added to the plates containing oil, it displaced the oil showing a zone of displacement of $4.8 \mathrm{~cm}$.

In BATH assay, after mixing aqueous suspension of washed microbial cells with a distinct volume of a hydrocarbon, petrol for $2 \mathrm{~min}$, the two phases were allowed to

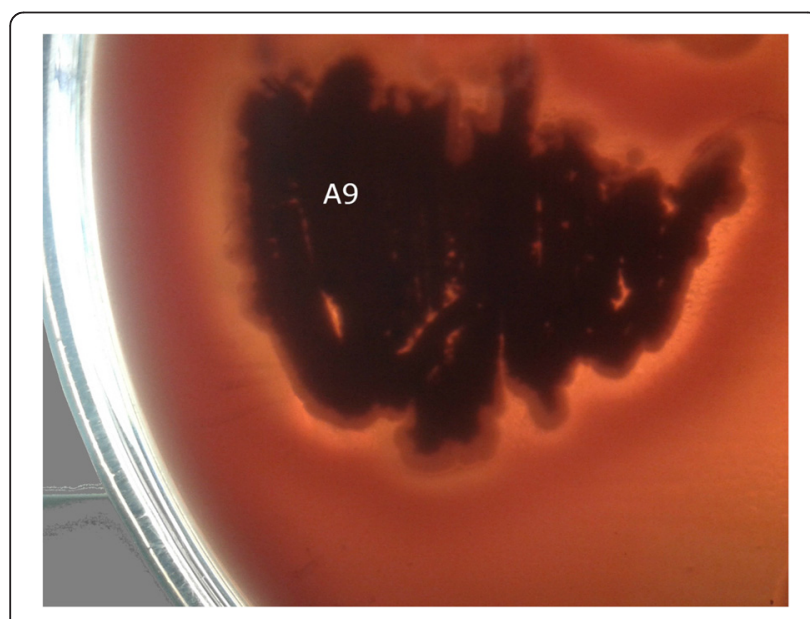

Figure 1 Biosurfactant assay. Hemolysis activity of Isolate A9. separate. Hydrophobic cells were bound to hydrocarbon droplets and had risen with the hydrocarbon. They were removed from the aqueous phase. The turbidity of the aqueous phase was measured. The decrease in the turbidity of the aqueous phase correlates to the hydrophobicity of the cells. The percentage of cells bound to the hydrophobic phase $(\mathrm{H})$ was found to be $54 \%$.

In penetration assay, the presence of biosurfactant was confirmed since the hydrophilic liquid break through the oil film barrier into the paste. The silica is entering the hydrophilic phase and the upper phase changed from clear red to cloudy white within $15 \mathrm{~min}$. The described effect relies on the phenomenon that silica gel is entering the hydrophilic phase from the hydrophobic paste much more quickly if biosurfactants are present. Biosurfactant-free supernatant will turn cloudy but stay red.

In emulsification assay, screening was done by adding $2 \mathrm{~mL}$ of diesel fuel to $1 \mathrm{~mL}$ of culture supernatant and kept overnight. Around 60\% emulsification was observed after $24 \mathrm{~h}$.

\section{Polythene and plastic biodegradation}

Polythene degradation is noticed by $22 \%$ weight loss whereas plastic degradation is noticed by $10 \%$ weight loss in A9 isolate after 2 months compared to negative control (Figure 2).

The weight loss in the polythene and plastic after 2 months implies that the organism uses polythene/plastic for their partial degradation. They colonize to form biofilm due to their hydrophobicity which aids in polymer biodegradation activity as discussed by Usha et al. [18]. In the primary degradation, the main chain cleaves leading to the formation of low-molecular weight fragments (oligomers), dimers, or monomers as discussed elsewhere $[18,19]$. The degradation is due to the extra cellular enzyme secreted by the organism. These low molecular weight compounds are further utilized by the microbes as carbon and energy sources. The resultantbroken down fragments must be completely used by the microorganisms; otherwise, there will be potential disruption in environmental cycle and resultant health consequences as discussed elsewhere $[19,20]$.

\section{Diesel biodegradation}

During the primary step of diesel biodegradation, the strain A9 showed the fastest color change in Bacto Bushnell Haas broth medium resulting in decrease of absorbance leading to highest biodegradation (Figure 3). The same isolate was further tested for vapor phase transfer method. The actinomycetes after 6 days showed better growth confirming to be a better hydrocarbon degrader. The color change in Bacto Bushnell 


\section{Polythene \& Plastic Biodegradation}

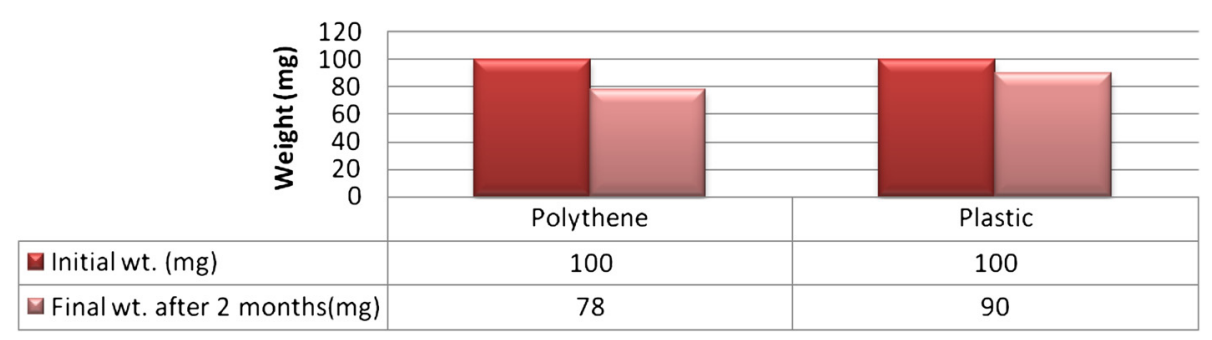

Figure 2 Polythene and plastic biodegradation pattern exhibited by A9 isolate.

Haas broth medium during the primary step of diesel biodegradation is mainly due to the reduction of the indicator by the oxidized products of hydrocarbon degradation as discussed by Smita et al. [13]. Hence, the given isolate was considered to be potential hydrocarbon oxidizers.

The strain A9 which showed effective biosurfactant and biodegradation properties was identified both in morphological and molecular level.

The isolate produced irregular, raised, grey white colonies with light yellow substrate mycelium on ISP2 agar surface. Dark brown melanin pigment was produced on ISP7 agar medium and no soluble pigments were produced by the isolate. By viewing under $\times 1,000$ magnification, gram-positive rods with rounded ends, branched hyphae with non-motile spores were found. Therefore, based on actinomycetes identification key as discussed elsewhere $[15,16]$, the isolate was assigned to the genus Nocardiopsis (Table 2).

Though it was assigned to the genus Nocardiopsis, the strain did not match with any of the given species. Hence, molecular characterization by $16 \mathrm{~S}$ rRNA ribotyping and phylogeny analysis was carried out in order to identify isolate A9 up to species level.

\section{Phylogenetic analysis and species identification}

Using BLAST search in the NCBI data bank, sequences homologous to $16 \mathrm{~S}$ rRNA gene of the isolate A9 were collected. The DNA sequences were aligned and phylogenetic tree was constructed using MEGA software (bootstrap method) as described by Tamura et al. [15] (Figure 4). The evolutionary history was inferred using the neighbor-joining method. The percentage of replicate trees in which the associated taxa clustered together in the bootstrap test $(1,000$ replicates) was shown next to the branches. Comparison of 16S rRNA nucleotide gene sequence of the isolated strain A9 with corresponding Nocardiopsis sequences clearly showed that the organism form a distinct phyletic line with Nocardiopsis genera. The isolate was closely related to the type strain of Nocardiopsis synnemataformans sharing a $16 \mathrm{~S}$ rRNA gene sequence similarity of $99 \%$. Hence, the molecular results support the classification of the isolate as a new strain which

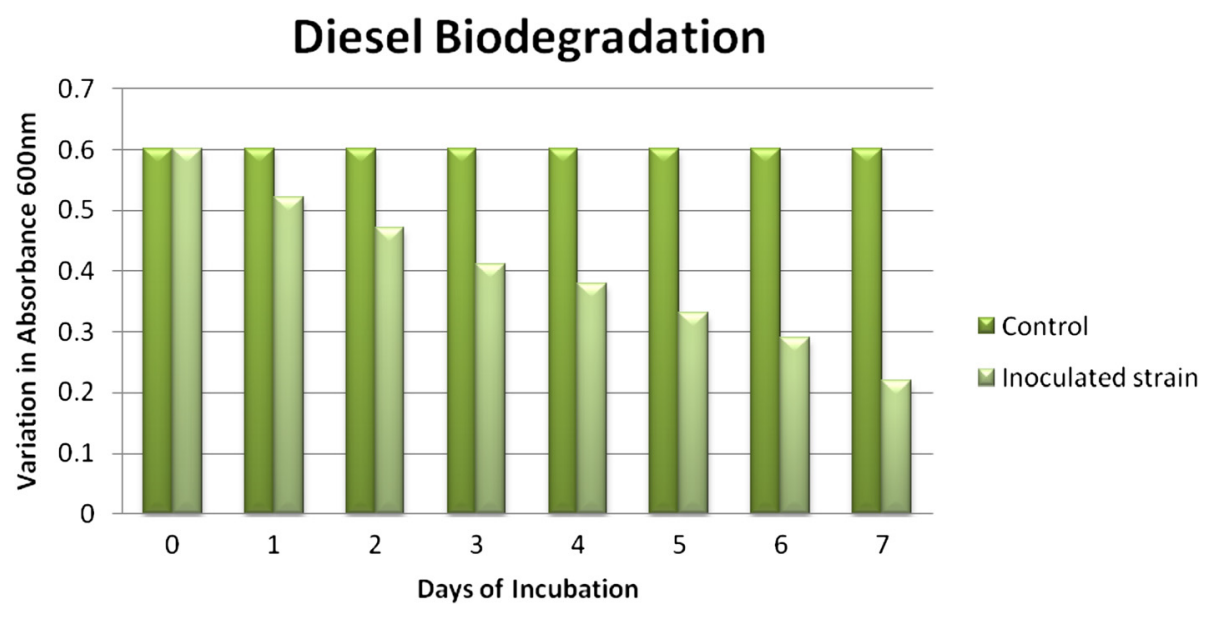

Figure 3 Diesel biodegradation pattern exhibited by A9 isolate. 
Table 2 Cultural characteristics of the isolate A9

\begin{tabular}{lllllll}
\hline Medium & \multicolumn{5}{l}{ Colony characters } \\
\cline { 2 - 6 } & Growth & Aerial mycelium & Basal mycelium & Color on reverse side & Soluble pigment & Melanin production \\
\hline ISP-1 & ++ & White & Colorless & Reddish brown & Reddish brown & - \\
ISP-2 & +++ & White & Cheese like & Reddish brown & Reddish brown & - \\
ISP-4 & +++ & White & Cheese like & Reddish brown & Reddish brown & - \\
ISP-5 & ++ & Dull White & Colorless & Reddish brown & - & - \\
ISP-6 & ++ & White & Cheese like & Reddish brown & - & - \\
ISP-7 & + & White & Cheese like & Brown & Brownish & + \\
SCA & +++ & White & Cheese like & Light olive green & Light green & - \\
NA & + & White & Cheese like & Reddish brown & Reddish brown & - \\
SDA & +++ & White & Cheese like & Reddish brown & Reddish brown & - \\
Microscopy & Gram-positive rods with rounded ends; branched hyphae with spores; non-motile & &
\end{tabular}

+, less; ++, moderate; +++, good, +/-, doubtful.

was named as Nocardiopsis sp. mrinalini9. The partial 16S rRNA sequence of isolate A9 (1,061 bp) was deposited in Genbank under the accession number KJ909126. Still, DNA-DNA hybridizations, phenotypic comparisons, and chemotaxonomic analysis need to be performed to confirm its novelty.

\section{Conclusion}

In this paper, we have reported the isolation and identification of Nocardiopsis sp. mrinalini9 with remarkable biosurfactant and biodegradation capacity. It was also noted that the same isolate remains endophytic to Neem leaves also as described by Mrinalini et al. [21]. Compared to bacteria and fungi, actinomycetes possess greater potential to degrade hydrocarbons [19,22,23]. Especially, Nocardiopsis sp. seems to have higher biosurfactant and biodegradation value $[19,24]$ compared to Streptomyces sp. which showcases better efficacy of rare actinomycetes. To the best of our knowledge, the novelty lies in the fact that not much research has been carried out on rare actinomycetes present in medicinal plants of Western Ghats of India with regard to its biosurfactant and biodegradation

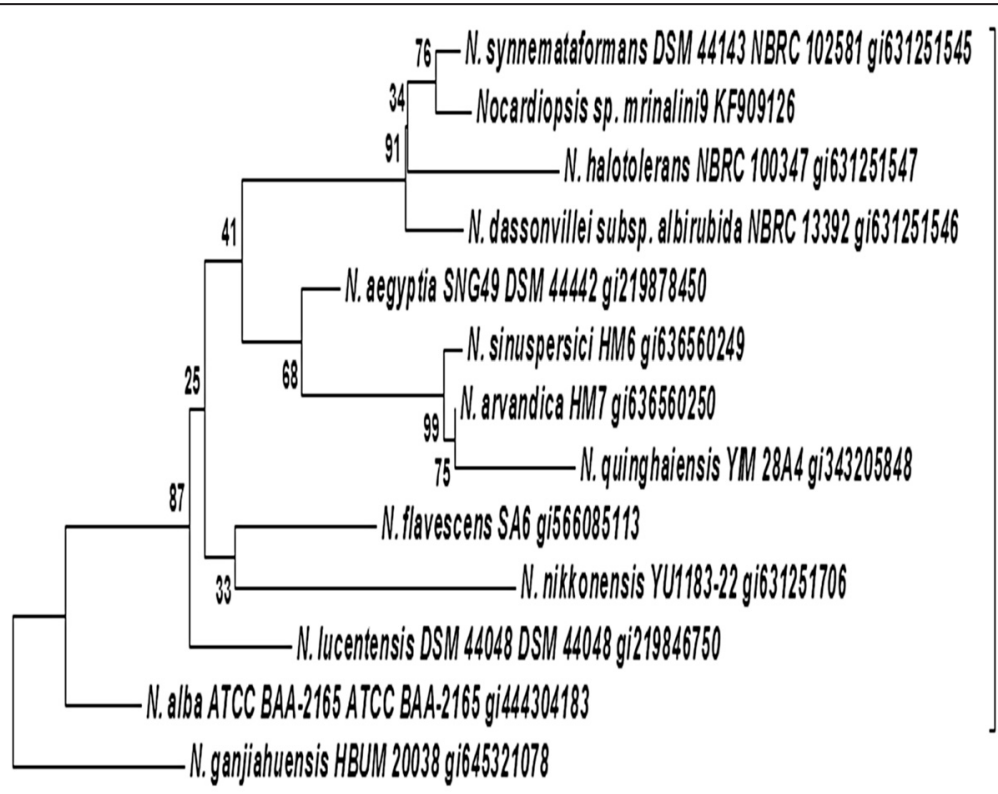

0.002

Figure 4 Phylogram depicting the taxonomic position of Nocardiopsis sp. mrinalini9. 
activity. Further studies are in progress with respect to the extraction and purification of biosurfactant from Nocardiopsis sp. mrinalini9 which will have wider applications in industrial process and bioremediation. Microorganisms residing in the floral environment are diverse and unique. Intensive studies must be carried out to unravel its unexhausted reserve of bio-metabolites.

\section{Competing interests}

The authors declare that there is no conflict of interests regarding the publication of this article.

\section{Authors' contribution}

MJS designed the whole study and carried out the experiment while PS guided the first author and helped in manuscript preparation. Both authors read and approved the final manuscript.

\section{Acknowledgement}

We are thankful to the authorities of Nirmala College for Women, Coimbatore, Tamil Nadu, for providing the necessary facilities. The first author is sincerely grateful to University Grants Commission, Government of India, for providing the award of Junior Research Fellowship in Science to pursue the research work. We are also thankful to Yaazh Xenomics, Chennai, for 165 rRNA ribotyping service.

Received: 4 November 2014 Accepted: 23 December 2014

Published online: 31 January 2015

\section{References}

1. Youssef NH, Duncan KE, Nagle DP, Savage KN, Knapp RM, Mclnerney MJ (2004) Comparison of methods to detect biosurfactant production by diverse microorganism. J Microbiol Meth 56:339-347

2. Siciliano SD, Fortin N, Mihoc A, Wisse G, Labelle S, Beaumier D, Ouellette D, Roy R, Whyte LG, Banks MK, Schwab P, Lee K, Greer CW (2001) Selection of specific endophytic bacterial genotypes by plants in response to soil contamination. Appl Environ Microbiol 67:2469-2475

3. Barac T, Taghavi S, Borremans B, Provoost A, Oeyen L, Colpaert JV, Vangronsveld J, Van der Lelie D (2004) Engineered endophytic bacteria improve phytoremediation of watersoluble, volatile, organic pollutants. Nat Biotechnol 22:583-588

4. Qin S, Li J, Chen HH, Zhao GZ, Zhu WY, Jiang CL, Xu LH, Li WJ (2009) Isolation, diversity, and antimicrobial activity of rare actinobacteria from medicinal plants of tropical rain forests in Xishuangbanna. China Appl Environ Microbiol 75:6176-6186

5. Carillo P, Mardarz C, Pitta-Alvarez S (1996) Isolation and selection of biosurfactant producing bacteria. World J Microbiol Biotechnol 12:82-84

6. Deepika L, Kannabiran K (2010) Biosurfactant and heavy metal resistance activity of Streptomyces spp. isolated from saltpan soil. Br J Pharmacol Toxicol 1(1):33-39

7. Yousaf S, Andria V, Reichenauer TG, Smalla K, Sessitsch A (2010) Phylogenetic and functional diversity of alkane degrading bacteria associated with Italian ryegrass (Lolium multiflorum) and Birdsfoot trefoil (Lotus corniculatus) in a petroleum oil-contaminated environment. J Hazard Mater 184:523-532

8. Morikawa M, Ito M, Imanaka T (1992) Isolation of a new surfactin producer Bacillus pumilus A-1, and cloning and nucleotide sequence of the regulator gene, psf-1. J Ferment Bioeng 74:255-261

9. Rosenberg M, Gutnick DL, Rosenberg E (1980) Adherence of bacteria to hydrocarbons: a simple method for measuring cell-surface hydrophobicity. FEMS Microbiol Lett 9:29-33

10. Maczek J, Junne S, Götz P (2007) Examining biosurfactant producing bacteria - an example for an automated search for natural compounds. In: Application Note CyBio AG

11. Cooper DG, Goldenberg BG (1987) Surface active agents from two Bacillus species. Appl Environ Microbiol 53:224-229

12. Kathiresan K (2003) Polythene and plastics - degrading microbes from the mangrove soil. Rev Biol Trop 51(3):629-634

13. Chaudhry S, Luhach J, Sharma V, Sharma C (2012) Assessment of diesel degrading potential of fungal isolates from sludge contaminated soil of petroleum refinery, Haryana. Res J Microbiol 7(3):182-190
14. Thijsse GJ, der Linden V (1961) Iso alkane oxidation by a Pseudomonas. Antonie Van Leeuwenhoek 27:171-179

15. Shirling EB, Gottlieb D (1966) Methods for characterization of Streptomyces species. Int J Syst Bacteriol 16:313-340

16. Williams ST, Sharpe ME, Holt JG (1989) Bergey's manual of systematic bacteriology, vol 4. Williams and Wilkins, Baltimore

17. Tamura K, Stecher G, Peterson D, Filipski A, Kumar S (2013) MEGA6: Molecular Evolutionary Genetics Analysis Version 6.0. Mol Biol Evol 30:2725-2729

18. Vasile, C (1993). Degradation and decomposition, in Handbook of polyolefins synthesis and properties, edited by C Vasile and R B Seymour (Marcel Dekker Inc, New York) pp: 479-509.

19. Usha R, Sangeetha T, Palaniswamy M (2011) Screening of polyethylene degrading microorganisms from garbage soil. Libyan Agr Res Center J Int 2(4):200-204

20. Narayan R (2006) Biobased and biodegradable polymer materials: rationale, drivers and technology exemplars. Am Chem Soc Symp 939(18):282

21. Singh MJ, Padmavathy S (2014) Isolation, screening and characterization of endophytic PGPR actinomycetes present commonly in Neem and Tulsi leaves - in vitro study (Tomato). Int J Recent Sci Res 5(3):574-579

22. Kannahi M, Sudha P (2013) Screening of polythene and plastic degrading microbes from Muthupet mangrove soil. J Chem Pharm Res 5(8):122-127

23. Idemudia MI, Nosagie OA, Omorede O (2014) Comparative assessment of degradation potentials of bacteria and actinomycetes in soil contaminated with motorcycle spent oil. Asian J Sci Tech 5(8):482-487

24. Gandhimathi RK, Seghal TA, Hema S, Joseph RRT, Shanmughapriya PS (2009) Production and characterization of lipopeptide biosurfactant by a sponge-associated marine actinomycetes Nocardiopsis alba MSA10. Bioproc Biosys Eng 32(6):825-835

\section{Submit your manuscript to a SpringerOpen ${ }^{\odot}$ journal and benefit from:}

- Convenient online submission

Rigorous peer review

- Immediate publication on acceptance

- Open access: articles freely available online

- High visibility within the field

- Retaining the copyright to your article

Submit your next manuscript at $>$ springeropen.com 